\title{
Catalyzing Disruptive Mobility Opportunities through Transformational Aviation Power
}

\author{
Nicholas K. Borer ${ }^{1}$ \\ NASA Langley Research Center, Hampton, Virginia 23681, USA
}

\begin{abstract}
Lightweight, efficient power production has been a pacing technology for aviation. Advances in airborne electric propulsion technology have enabled new aviation concepts in markets that previously were not dominated by aviation systems, largely because electric propulsion allows for efficient, integrated propulsion/aerodynamic/control solutions that were previously not practical with combustion-based power architectures. These new markets include automated package delivery, urban air mobility, and short-haul transportation. As these markets evolve, the impact of using electricity for airborne propulsion on an expanding mission set, as well as the sheer amount of energy consumed, will begin to challenge the energy harvesting and distribution paradigm as it exists today. Left unaddressed, these challenges could stymie the evolution of these new markets and mobility options. This paper identifies some of the potential systemic issues associated with the expanded use of electric propulsion and explores the requirements associated with alternate aviation power architectures. The recommended path includes the development of a new hybrid-electric aviation power architecture that can be used in conjunction with a portfolio of evolving battery-electric and combustion-based systems.
\end{abstract}

\begin{tabular}{ll} 
& \multicolumn{1}{c}{ Nomenclature } \\
AFDC & $=$ U.S. Department of Energy Alternative Fuels Data Center \\
$\mathrm{CO}_{2}$ & $=$ Carbon Dioxide \\
$\mathrm{DEP}$ & $=$ Distributed Electric Propulsion \\
$\mathrm{EIA}$ & $=$ General Aviation \\
$\mathrm{GA}$ & $=$ Gallon of Gasoline Equivalent energy \\
$\mathrm{GGE}$ & $=$ Lower Heating Value of fuel \\
$\mathrm{LHV}$ & $=$ Lawrence Livermore National Laboratory \\
$\mathrm{LLNL}$ & $=$ specific power of hybrid SOFC system \\
$\mathrm{MCP}$ & $=$ specific power of electric powertrain \\
$(P / m)_{h}$ & $=$ specific power of the sum of powertrain, hybrid system, and stored energy components \\
$(P / m)_{p}$ & $=$ Quadrillion (10 $)$ BTU \\
$(P / m)_{t o t a l}$ & $=$ Solid Oxide Fuel Cell \\
Quad & $=$ small Unmanned Aircraft System \\
$\mathrm{SOFC}$ & $=$ Urban Air Mobility \\
$\mathrm{sUAS}$ & $=$ efficiency of hybrid SOFC system \\
$\mathrm{UAM}$ & $=$ efficiency of electric powertrain \\
$\eta_{h}$ &
\end{tabular}

\section{Introduction}

In 2016, National Academies released a report detailing a research agenda to reduce aviation's contribution to global carbon emissions [1]. The report stated that aviation is responsible for $2-2.5 \%$ of global annual $\mathrm{CO}_{2} \mathrm{emissions}$ and although not the largest contributor, travel by air is growing, as is its share of emissions. In the United States, the report found that the transportation sector contributes to about $11 \%$ of total U.S. greenhouse gas emissions. Per the report, aviation contributes about $9 \%$ of transportation emissions, indicating that aviation contributes approximately

${ }^{1}$ Principal Investigator/Aerospace Engineer, Aeronautics Systems Analysis Branch, MS 442, AIAA Senior Member. 
$1 \%$ of total U.S. greenhouse gas emissions. The vast majority of greenhouse gas emissions from the transportation sector is $\mathrm{CO}_{2}$, which is largely associated with the combustion of petroleum-based fuels.

Given that combustion of petroleum is the dominant factor in aviation emissions, it is readily seen that reduction of $\mathrm{CO}_{2}$ emissions is more or less equivalent with an associated increase in total efficiency ${ }^{\dagger}$ : more efficient concepts require less fuel and therefore will expel less $\mathrm{CO}_{2}$. This efficiency change can come from the thermodynamic cycle that converts stored energy in the fuel to useful work, the mechanical and fluid mechanisms that convert the useful thermodynamic work into propulsion, or by changing the amount of required propulsive energy integrated over the aircraft mission (e.g., change in aerodynamic drag or change in mission needs/parameters). More efficient concepts require less stored energy onboard (fuel), which can be seen as reducing a portion of the aircraft operating cost, as well as reducing the $\mathrm{CO}_{2}$ emissions associated with the aircraft's mission.

Naturally, the National Academies report focused on the largest contributors of greenhouse gas emissions: over $90 \%$ of global civil aviation carbon emissions were attributed to aircraft with a seating capacity of 100 passengers or more, which are nearly exclusively powered by gas turbine engines. Research associated with this segment was seen by the National Academies as the most relevant to reduction of global aviation carbon emissions. Hence, the report recommended a research portfolio heavy on solutions that could affect this segment: increased propulsive efficiency (fans), increased thermodynamic efficiency (higher operating temperatures \& pressures), boundary layer ingestion (better airframe/propulsion integration), and small gas turbine engine cores (improved efficiency across thrust classes). The report also recommended increased research and development into alternative fuel feedstocks that could reduce the net carbon output of aviation propulsion. Finally, the report recommended investigation of electrical technologies for propulsion, including increased research infrastructure and development of improved aircraft systems, but this was focused on the megawatt-level as it was seen as most relevant to the power needs of the aviation sector. On the electric front, the report saw the merging of electric and turbine-based approaches as promising: turboelectric propulsion.

The report did not highlight emerging airborne electric propulsion technologies as a game-changer for the aviation segment in terms of global carbon emissions. However, the scope of the National Academies report did not include a broader analysis of how aviation can displace other transportation needs and markets that are not currently dominated by aviation solutions. The growing electrification of transportation solutions - particularly in ground vehicles - is a recognized trend, with projections that show electrically-powered vehicles may dominate future ground transportation markets within two decades [2][3]. These same forces, along with the emergence of new aviation markets enabled in part by airborne electric propulsion, have the potential to fundamentally alter aviation's role in the transportation sector. This paper explores the potential impact of airborne electric propulsion on existing and emerging aviation markets, as well as the impact on national energy distribution.. Section II identifies the target applications envisioned for airborne electric propulsion, and Section III identifies some of the systemic issues associated with aircraft design and national energy infrastructure planning that may arise. Section IV explores some notional aviation powertrains, and identifies requirements associated with an airborne power generation technology that could help "fill the gap" in the portfolio of electricity storage and generation solutions currently proposed for these markets.

\section{Background}

\section{A. Current State of Electric Propulsion in Aviation Applications}

The smallest aircraft have seen a recent, significant shift in propulsion architectures. Within the last two decades, advances in small electric motors, power electronics, microprocessors, and solid-state inertial measurement systems have converged to create a new aviation market for small, inexpensive, battery-electric unmanned aircraft. These started as easy-to-fly hobby aircraft and have already largely displaced the small, noisy, unreliable combustion engines used by radio control hobby enthusiasts in previous decades. The high efficiency and high power-to-weight ratio of the electric motors enable them to be distributed as both propulsors and control effectors (for example, using the rotors of a quad-rotor for lift, thrust, and control). The reliable, high-rate control interface of electric motors, combined with advanced, low-cost control electronics and software, makes these platforms substantially easier to use, requiring much less special training to operate. These features have offset the otherwise onerous energy storage barrier for electric propulsion. Batteries still have far less energy per unit mass than petroleum fuels, but the short duration and relatively low power requirements have made purely electric propulsion extremely popular in this hobby market.

\footnotetext{
$\dagger$ Total efficiency in this context refers to the ratio of the amount of useful transportation work, in terms of movement of a given amount of payload or people, to the amount of energy input into the system. The energy input into combustion is typically the integral of fuel flow rate over the mission time multiplied by the lower heating value of the fuel.
} 
As this electric aircraft propulsion technology has improved, it has expanded into wider markets. In general, these small aircraft, whether used for recreational or commercial purposes, are categorized as small Unmanned Aircraft Systems (sUAS). Companies such as Amazon have been investigating the use of sUAS for package delivery [4], and the concept of electric propulsion is very attractive due to the potential for increased reliability, low cost, and reduction in noise. By focusing operations on dense urban areas, delivery vendors can serve a wide network of users, with less encumbrance due to ground vehicle congestion and indirect routing. The short range of these missions lowers the impact of the poor energy storage capability associated with batteries.

Electric propulsion interest has also grown in the small General Aviation (GA) market. In GA, manned aircraft are flown for a mix of personal, business, and public use operations. Overall, operating costs per seat mile tend to be high, at least as compared to large commercial transport aircraft. This is largely due to the high maintenance costs and relatively poor efficiency of the combustion-based powerplants that serve this market - costs for engine maintenance and fuel can easily exceed $50 \%$ of the total direct operating cost of GA aircraft [5]. Electric propulsion has already crept into GA operations where range is less important, in a bid to reduce operating costs and increase reliability. Companies such as Pipistrel [6] have developed electric motor-gliders and training aircraft and see growth into higherperformance regions for hybrid-electric and eventually fully-electric systems.

Recently, interest has surged in the emerging Urban Air Mobility (UAM) market, which is looking to move passengers along intra-urban, on-demand routes that are otherwise poorly served by existing transportation paradigms - namely, automobiles or other ground transportation options. In general, the issues envisioned being resolved by UAM center on improvements in travel time by "flying over" congested routes, or by eliminating the non-direct routing (and multiple stops) associated with mass transit. For example, the Uber Elevate concept [7] seeks to use UAM to augment on-demand ground transportation services.

Finally, electric propulsion is a concept of recent interest in the regional commuter market. NASA-sponsored studies for short-haul and "thin-haul" commuters [8] show that electrically-powered concepts may have an advantage in operating costs that could make these low-demand routes more profitable (many of these routes are currently subsidized through the Essential Air Services program). Startup companies such as Zunum are developing batteryelectric and hybrid-electric small commuter aircraft that will have a very favorable seat-mile cost compared to today's fully-combustion-based concepts. In what may be seen as a vote of confidence, Boeing HorizonX and JetBlue Technology Ventures have announced backing of Zunum's concepts [9].

\section{B. Impact of Electric Propulsion on Transportation Markets}

Taken as a static market, the electric propulsion applications mentioned above will do little to change the emission/efficiency landscape of aviation. As properly noted in the National Academies report, these smaller segments of the aviation sector contribute less than $10 \%$ of all aviation emissions in the United States. In context with total transportation, in 2015 aviation accounted for an estimated 9\% of the transportation sector's contribution to greenhouse gases in the United States [10], as seen in Fig. 1. Doubling the efficiency of small aircraft, which contribute less than $10 \%$ of aviation emissions, a sector that only contributes $9 \%$ to U.S. transportation sector emissions and $2 \%$ to global emissions, seems to make little difference.

However, these opportunities do not exist in a static market. Amazon Prime Air is not necessarily looking to displace much of the aviation market - they are looking to remove delivery trucks from crowded roads. Uber Elevate is not looking to displace GA flights - they are looking to reduce the number of cars in congested cities. Zunum, and by extension Boeing and JetBlue, are not looking to replace existing routes - they are looking to add to their market by providing a cost-competitive alternative for short-range, inter-city routes that currently do not exist because they are not currently cost-competitive with ground transportation. In almost all cases, electric propulsion for aviation is looking to assault the largest contributors to emissions/inefficiency in the transportation sector - light cars and trucks ( $60 \%$ of U.S. transportation emissions) and heavy trucks and buses ( $23 \%$ of transportation emissions) [10].

It can certainly be argued that the ground transportation market is not static as well. Ride-hailing services, such as Uber and Lyft, are disruptive to the notion of personal automobile ownership, particularly in larger cities. That does not necessarily replace the emissions from such vehicles on trips, but it can increase the utility of vehicles and potentially displace congestion with increased ride-sharing. Fully-electric and hybrid-electric automobiles are a growing part of the ground transportation segment, a trend which has the capability to reduce emissions and increase efficiency. Electric and natural gas buses and trucks also help to reduce the contribution of emissions in this sector. However, that is not to say that concepts such as electric sUAS, UAM, and short/thin-haul aircraft will not be competitive. In fact, on a productivity basis, vehicles that are unencumbered by indirect ground routing, congestion, and even the friction of contact of wheels on the ground, can be just as efficient, if not more efficient, on a per seatmile basis than electrically-powered wheeled ground vehicles [7]. The faster speeds possible in flight vs. ground transportation enable increased throughput at similar, if not better, efficiency. 


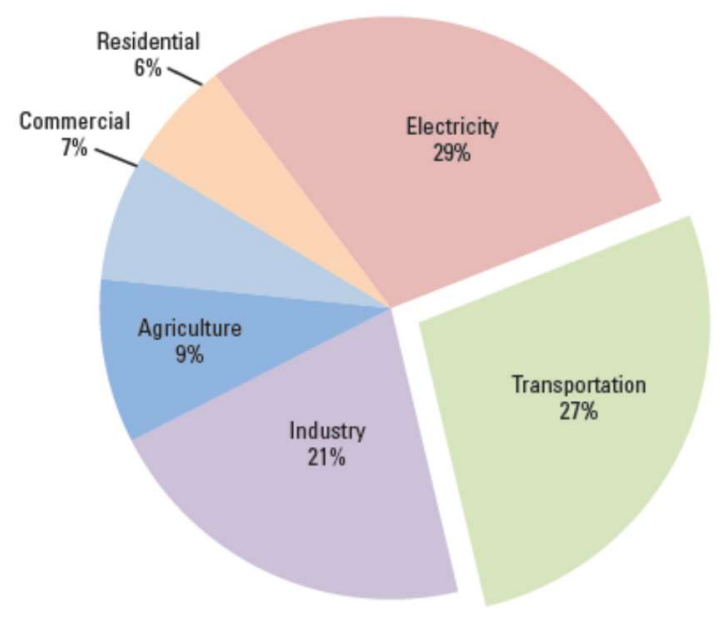

Share of U.S. GHG Emissions by Sector, $2015^{3,4}$

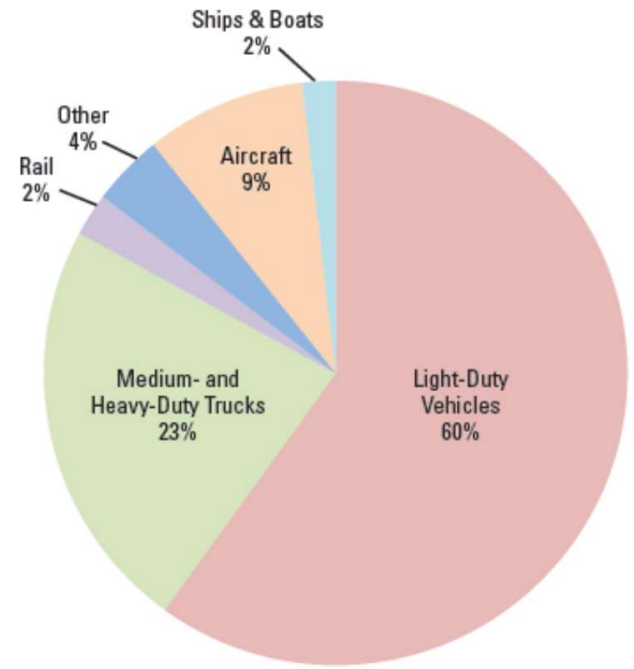

Share of U.S. Transportation Sector GHG Emissions by Source, 20154,5

Fig. 1 Share of U.S. greenhouse gas emissions by sector and transportation source in 2015 [10].

\section{Energy Use and Challenges for Aviation Applications}

One of the oft-stated benefits of electric propulsion is the dramatic increase in efficiency of the propulsion system in terms of use of the energy stored on the vehicle. NASA's Scalable Convergent Electric Propulsion Technology Operations Research (SCEPTOR) Project is developing the X-57 "Maxwell" flight demonstrator, which aims to show up to a fivefold reduction in energy consumption vs. a conventional gasoline-powered aircraft through the use of Distributed Electric Propulsion (DEP) technology [11]. Approximately a threefold reduction in energy can be attributed to the change from an Otto cycle gasoline engine of around 30\% thermal efficiency to X-57's electric powertrain, which will likely exceed an efficiency of $90 \%$. These projections do not account for system-level issues associated with matching the range or payload of either aircraft, given that the X-57 is an "X-plane" technology demonstrator, but do account for how energy is converted from its stored state on the aircraft (either as fuel on the conventional aircraft or in the batteries on the X-57) to the shaft power that turns the propellers.

However, the differences in efficiency associated with the gasoline-powered aircraft vs. the all-electric X-57 do not speak to global efficiency of operation. Electricity must be harnessed or otherwise generated on the ground to charge the X-57's batteries, and the method of electricity generation often involves the combustion of fuels. A common criticism of fully-electric vehicles is that the fuel used and emissions created during generation of the electricity that is stored in the vehicle offsets the vehicle-level efficiency benefits.

As noted above, it is not necessarily efficiency, or efficiency alone, that drives selection of a particular propulsion architecture for aircraft. In the case of the X-57, the use of electric propulsion enables the use of DEP technology, which further reduces the drag of the aircraft at cruise - meaning that less thrust needs to be produced compared to a non-DEP configuration designed to the same payload and range requirements [11]. Hence, DEP can enable greater aerodynamic efficiency that can lead to an overall system-level reduction in energy use. The potential changes in system reliability, maintainability, and coupled aero-propulsive control for small aircraft markets, combined with an increase in system-level efficiency (and therefore reduction in energy cost and overall emissions), still point towards the potential for electric propulsion to be a game-changer in some markets.

\section{A. Energy Sources and Consumers}

To help identify the system-level efficiency of electric propulsion for aircraft, it is necessary to identify energy flows to end sectors. In recent years, Lawrence Livermore National Laboratory (LLNL) and the U.S. Department of Energy have published yearly Energy Flow Charts to show the relationship between energy sources and energy 
consumers [12]. This information is compiled from the U.S. Energy Information Administration (EIA), which gathers monthly data on energy use in the United States [13]. The 2015 Energy Flow Chart ${ }^{\ddagger}$ is shown in Fig. 2.

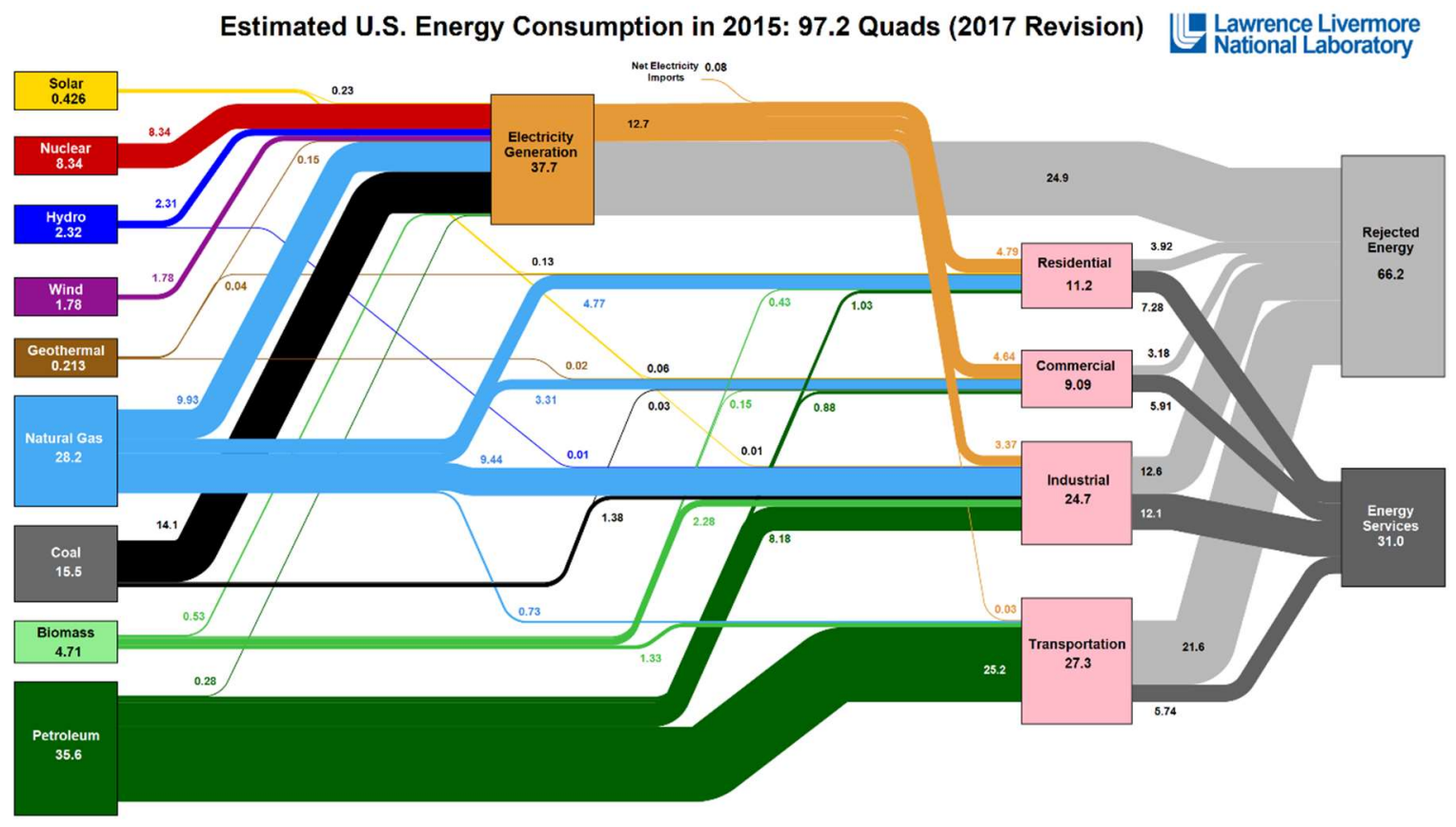

Fig. 2 Chart of energy flow estimates in the United States for 2015 [12].

Fig. 2 indicates that electricity generation accounted for 37.7 quadrillion $\left(10^{15}\right)$ BTUs ${ }^{\S}$ ("Quads") of energy consumed out of a total U.S. consumption of 97.2 Quads in 2015, or about $39 \%$ of the total. Of these 37.7 Quads of energy input, a total of 12.7 Quads of electricity were generated, indicating an average efficiency of $34 \%$ across all sources. However, electricity is not an end user sector; rather, it is used by other sectors (residential, commercial, industrial, and transportation) to be converted into useful work or energy. Of note, the transportation sector consumed 27.3 Quads of energy in 2015, of which only 0.03 Quads of energy came from electricity generation. Accounting for this, it can be seen that about $28 \%$ of total U.S. energy consumption in 2015 was due to transportation, one of the biggest end users of energy in the United States and the smallest consumer of electricity. Of the 27.3 Quads of energy consumed by the transportation sector, an estimated 5.74 Quads of useful work were performed, for an average efficiency of $21 \%$.

Electric motors used for propulsion in aviation will be used to turn a propeller or fan to produce thrust. The typical efficiency of a propeller, which measures the useful thrust work output vs. the shaft work input to spin the propeller, is around $80 \%$. Assuming a 30\% efficient Otto cycle gasoline engine, such as one type typically used in general aviation aircraft, therefore results in a total efficiency of around $24 \%$, in terms of converting energy from the stored fuel into thrust production. An electric powertrain can be in excess of $90 \%$ efficient, but it is encumbered by losses encountered with power transmission from the electricity source to the charging station, as well as losses during battery charging. Assuming that the power transmission and battery charging efficiencies are around $95 \%$ each, the total efficiency of a propeller-driven battery-electric aircraft is around $65 \%$ in terms of electrical energy from the grid to the generation of thrust $(0.95 \times 0.95 \times 0.9 \times 0.8)^{* *}$. From a $34 \%$ efficient electrical grid, this results in a total efficiency of about $22 \%$ from energy source to thrust generation. Granted, there are a number of assumptions that can be traded here, but this shows that, from an energy-source-to-thrust generation standpoint, generation of a given amount of thrust in a fully electric aircraft in the X-57 size class is more or less equivalent (if not slightly worse) to the efficiency of the traditional combustion-based solution. Hence, the major savings to be realized in this scenario have to do with the aerodynamic efficiencies that can be realized - that is, requiring less thrust generation in the first

\footnotetext{
* Energy data from 2015 is largely used in this paper to provide direct comparison to the 2015 EPA emissions data.

$\S 1 \mathrm{BTU}=0.293 \mathrm{Wh}$. For convenience, Quads will be used to reference the LLNL data, but metric units will otherwise be used throughout this paper.

${ }^{* *}$ Total transportation efficiency for electric: (power transmission) x (battery charging) x (powertrain) x (propeller).
} 
place. It is important to also note that this trend will likely favor thrust generation from electricity for smaller vehicles, given that thermal efficiencies of combustion engines tend to be poorer at small scales, and will favor combustionbased thrust production for larger vehicles, where the thermal efficiency of combustion engines scales favorably at large scales.

Any number of excursions and arguments can be made regarding these numbers. When one examines trends and energy policy in general, it is seen that the efficiency of electricity generation is generally improving. This is due to policies that enable growth of renewable energy resources, notably the large growth in solar and wind power generation that has been seen in the past decade. Market forces have helped as well - changes in petroleum extraction methods and growth in natural gas use have exacerbated the policy-based decline of coal as a source of energy. LLNL and EIA data, summarized in Table 1, show that natural gas has experienced the biggest energy supply increase over the 2011-2016 timeframe - 3.6 Quads - overshadowing the increase of 0.94 Quads of wind energy, 0.43 Quads of solar energy supply, and 0.34 Quads of biomass energy supply increases over the same timeframe. Natural gas can be used to fuel ground-based gas turbines, and LLNL/EIA data indicate that, on average, natural gas is $42 \%$ efficient for U.S. electricity generation [13], with the largest, newest combined-cycle units able to exceed $60 \%$ [14]. These forces have reduced the coal energy supply by 5.5 Quads over the 2011-2016 timeframe. Coal plants tend to be older and less efficient, averaging approximately $32 \%$ efficiency per LLNL and EIA data. Although U.S. policy may become more favorable to coal power generation in the future, it may not be enough to overcome market forces - and the market is using more efficient cycles for electricity generation as a way to reduce generation costs.

Table 1 Changes in U.S. Energy Sources, 2011-2016 (Quadrillion BTUs)

\begin{tabular}{|c|c|c|c|c|c|c|c|}
\hline Source & 2011 & 2012 & 2013 & 2014 & 2015 & 2016 & Change \\
\hline Solar & 0.158 & 0.235 & 0.320 & 0.427 & 0.426 & 0.587 & +0.429 \\
\hline Nuclear & 8.26 & 8.05 & 8.27 & 8.33 & 8.34 & 8.42 & +0.16 \\
\hline Hydro & 3.17 & 2.69 & 2.56 & 2.47 & 2.32 & 2.48 & -0.69 \\
\hline Wind & 1.17 & 1.36 & 1.60 & 1.73 & 1.78 & 2.11 & +0.94 \\
\hline Geothermal & 0.226 & 0.227 & 0.201 & 0.202 & 0.213 & 0.230 & +0.004 \\
\hline Natural Gas & 24.9 & 26.0 & 26.6 & 27.5 & 28.2 & 28.5 & +3.6 \\
\hline Coal & 19.7 & 17.4 & 18.0 & 17.9 & 15.5 & 14.2 & -5.5 \\
\hline Biomass & 4.41 & 4.32 & 4.49 & 4.78 & 4.71 & 4.75 & +0.34 \\
\hline Petroleum & 35.3 & 34.7 & 35.1 & 34.8 & 35.6 & 35.9 & +0.6 \\
\hline
\end{tabular}

Fig. 2 also shows that nearly all of the energy that is consumed by the transportation sector is stored as petroleum - over $92 \%$. The balance of the remaining energy is still in a form that is stored and distributed in a similar fashion biomass and natural gas - with a tiny fraction coming from electricity. Taken to the limit, if the 5.74 Quads of useful transportation work in 2015 were all provided from electricity at a $65 \%$ transportation sector efficiency, the U.S. would need to increase useful electricity production by 8.83 Quads - an increase in electricity output of nearly $70 \%$. This contrasts with the trends seen from 2010-2016, where electrical energy output actually decreased by 0.6 Quads.

\section{B. Impact of Airborne Electric Propulsion on Aircraft and Energy Distribution Systems}

From an aviation standpoint, as noted above, less than $10 \%$ of the aviation market may stand to benefit from electric propulsion as it exists today. However, advances in aviation electric propulsion are not necessarily being used to displace existing aviation markets - rather, they are being used to displace existing ground transportation markets, or used to capture latent demand. Per the data in Fig. 1, a change in $10 \%$ of the aviation market likely only affects about $0.9 \%$ of the transportation sector energy use. Yet, a change in $10 \%$ of the light-duty vehicle market, or $10 \%$ of the medium and heavy-duty truck market, would affect $6 \%$ and $2.3 \%$ of the transportation sector energy use, respectively. Although it is very difficult to speculate how much of these markets may be impacted by disruptive technologies in sUAS, UAM, or short/thin-haul, it is readily seen that it is possible to have a much larger impact on energy use and emissions by targeting aviation concepts that displace ground vehicle missions, rather than replace missions currently flown by aircraft.

It is unclear how demand will materialize and impact electricity generation and distribution in the United States, but the challenges can be readily seen by examining the individual operations. Individually, UAM operations represent significantly more challenging local energy and power requirements, simply due to the much higher weight of these vehicles (as compared to sUAS). Generalizing the amount of energy used per flight hour is a challenging exercise, though some relevant statistics can be pulled from recent studies. McDonald and German's study of the Dallas UAM market for Uber indicates that a $400 \mathrm{~kW}$ charging station can support five-minute charges under "surge" demand, 
which equates to $33 \mathrm{kWh}$ of electricity transmitted to the aircraft storage batteries per trip [15], assuming $100 \%$ efficiency. To put these two numbers in perspective, the average home in the United States uses approximately 30 $\mathrm{kWh}$ of electricity per day [16], and the average grocery store requires $285 \mathrm{~kW}$ to operate [17]. Energy demands, and power associated with rapid battery charge, vary greatly with trip length and vehicle type, but the types of operations envisioned by Uber Elevate favor fairly short-duration, short-range, high-speed trips. This high-throughput operation is necessary to increase vehicle utilization and, therefore, reduce overall life-cycle costs. It also represents a significant challenge to flight operations as compared to how they are conducted today.

Another significant challenge with UAM operations is associated with the well-known issue of the specific energy of batteries. State-of-the-art batteries may exceed $200 \mathrm{Wh} / \mathrm{kg}$, but this pales in comparison to the 12,000 Wh/kg specific energy of the petroleum-based fuels used in aviation today [18]. This is not to say that a 60x improvement in battery specific energy is necessary before electric concepts make sense - the efficiency, configurations, and missions flown by electric UAM concepts are markedly different than those in today's aviation sector - but it does highlight one of the major challenges associated with electric flight. McDonald and German indicate that battery-electric operations become feasible for the Dallas market with battery packs at $400 \mathrm{Wh} / \mathrm{kg}$, and limited options are potentially available at $300 \mathrm{Wh} / \mathrm{kg}$ [15]. However, these numbers come with considerable caveats. Aviation safety standards for high-voltage, high-capacity batteries are still evolving, as are practices related to depth of discharge for economical operation. For example, the battery cells used for the X-57 are approximately $200 \mathrm{Wh} / \mathrm{kg}$, but the battery packs are closer to $130 \mathrm{Wh} / \mathrm{kg}$ after accounting for packaging safety and operational depth of discharge constraints [19].

Practically, the knockdown factor on battery specific energy for UAM or short/thin-haul operations may even be greater than X-57's factor, given that X-57 is not operating with major reserves due to being restricted to a particular test range and set of operational conditions. The relatively low specific energy of batteries results in a dramatic change in the reserve mission capability of the vehicle. Current operational reserves for aircraft range from 20 minutes to more than 45 minutes of energy stored onboard the aircraft, depending on the type of aircraft and operation. The Dallas UAM market described by McDonald and German indicates that a typical trip is less than 10 minutes, and that the vehicle will need to recharge at every mission stop to reduce the penalty associated with carrying excess battery to handle multiple trips [15]. Hence, even a 20-minute reserve seems impractical, if not impossible, for such weightconstrained systems. To be viable, UAM operations will require a change in definition for operations, including a dramatic reduction in required reserves.

Altogether, while these challenges may seem daunting, the potential for reward has brought in billions of dollars of private capital. To fundamentally transform the mechanisms of transportation of people and goods as we know it today is too great an opportunity to ignore. Electric propulsion is one of the cornerstone technologies associated with these emerging markets, and the government and private sector are investing heavily in resolving these challenges. However, the concepts considered to date have largely been purely battery-electric or, to a lesser extent, combustionbased hybrid-electric concepts. A time-honored technique used for hedging against future uncertainty is to adopt a portfolio of independent approaches. Certainly, betting on the correct single "winner" may provide for the greatest return, but it comes with significant risk. A portfolio of options - including the use of other energy production, consumption, and storage modalities - may be able to provide the best balance of risk and return for future airborne electric propulsion.

\section{Aviation Power Architectures}

As noted earlier, electric propulsion in aviation tends to favor smaller aircraft. In order to investigate a possible portfolio of options, it is necessary to first look at existing and emerging solutions for aviation propulsive power for smaller aircraft. Generally, the power needs for smaller aircraft are currently filled by gas turbine and reciprocating engines, though some recent examples of battery-electric aircraft are also considered. Some relevant aviation powertrains are shown in Table 2.

These seven powertrains show the dramatic differences in power-to-weight ratio and efficiency possible with different powertrain architectures. Although today's large gas turbine engines for aviation use can achieve thermal efficiencies of up to $55 \%$, the physics that govern the scaling of such architectures limit the possible efficiency at lower power levels. These lower efficiencies increase operating costs in the form of additional fuel required per mission, which is especially troublesome for smaller aircraft since the operating costs are amortized over fewer passenger seats. Other factors come into play as well, but overall, for smaller power requirements (under $500 \mathrm{~kW}$ ), reciprocating engine solutions tend to dominate small aircraft powertrain selection. Hence, Table 2 lists one turbine engine and three reciprocating engine solutions, which span the technology range available (including direct-drive, spark-ignition, and compression-ignition solutions). Although the aviation sector has yet to fully embrace electric propulsion, data on recent electric motors designed for aviation use are included in this table as well. 
Table 2 Representative Powertrains for Small Aircraft

\begin{tabular}{|l|l|l|l|l|l|l|}
\hline Powertrain & Type & Max. Cont. Power & Mass & Eff. & Sp. Power & Ref. \\
\hline $\begin{array}{l}\text { Pratt \& Whitney } \\
\text { PT6A-42 }\end{array}$ & Turbine - jet fuel, geared & $634 \mathrm{~kW}$ & $183 \mathrm{~kg}$ & $23 \%$ & $3.5 \mathrm{~kW} / \mathrm{kg}$ & {$[20]$} \\
\hline $\begin{array}{l}\text { Continental IO- } \\
\text { 550N }\end{array}$ & $\begin{array}{l}\text { Reciprocating - gasoline, } \\
\text { direct drive, air-cooled }\end{array}$ & $231 \mathrm{~kW}$ & $204 \mathrm{~kg}$ & $28 \%$ & $1.1 \mathrm{~kW} / \mathrm{kg}$ & {$[21]$} \\
\hline Rotax 912S & $\begin{array}{l}\text { Reciprocating - gasoline, } \\
\text { geared, liquid-cooled }\end{array}$ & $69 \mathrm{~kW}$ & $61 \mathrm{~kg}$ & $32 \%$ & $1.1 \mathrm{~kW} / \mathrm{kg}$ & {$[22]$} \\
\hline Austro AE300 & $\begin{array}{l}\text { Reciprocating - diesel, } \\
\text { geared, liquid-cooled }\end{array}$ & $114 \mathrm{~kW}$ & $185 \mathrm{~kg}$ & $42 \%$ & $0.6 \mathrm{~kW} / \mathrm{kg}$ & {$[23]$} \\
\hline Joby JM-X57K & $\begin{array}{l}\text { Electric, direct-drive, air- } \\
\text { cooled, dual inverter }\end{array}$ & $60 \mathrm{~kW}$ & $37 \mathrm{~kg}$ & $>92 \%{ }^{\dagger \dagger}$ & $1.6 \mathrm{~kW} / \mathrm{kg}$ & {$[19]$} \\
\hline $\begin{array}{l}\text { Siemens } \\
\text { Dynadyn }\end{array}$ & $\begin{array}{l}\text { Electric, geared, liquid- } \\
\text { cooled }\end{array}$ & $60 \mathrm{~kW}$ & $14 \mathrm{~kg}$ & $>92 \%$ & $4.6 \mathrm{~kW} / \mathrm{kg}$ & {$[24]$} \\
\hline Siemens SP260D & $\begin{array}{l}\text { Electric, direct-drive, } \\
\text { liquid-cooled }\end{array}$ & $230 \mathrm{~kW}$ & $60^{\ddagger \dagger} \mathrm{kg}$ & $>92 \%$ & $3.8 \mathrm{~kW} / \mathrm{kg}$ & {$[25]$} \\
\hline
\end{tabular}

\section{A. Powertrain Integration into Aircraft}

The data from Table 2 seem to indicate that electric powertrains should be the architecture of choice for small aircraft; they are capable of specific power numbers that rival gas turbines and have unmatched efficiency - assuming one is able to store electricity on the host aircraft efficiently. Yet, it is this storage modality that is the source of one of the more vexing problems for electric aviation. Table 3 provides some information on relevant aircraft that use some of the powertrains listed previously in Table 2 .

Table 3 Representative Aircraft/Powertrain Integrations

\begin{tabular}{|c|c|c|c|c|c|}
\hline Aircraft & Powertrain & $\begin{array}{l}\text { Max. Stored } \\
\text { Energy Mass }\end{array}$ & $\begin{array}{l}\text { Max. Shaft } \\
\text { Work }\end{array}$ & $\begin{array}{l}\text { Time at Max. } \\
\text { Cont. Power }\end{array}$ & Ref. \\
\hline Beechcraft C-12A & 2x PT6A-42 & $1660 \mathrm{~kg}$ & $4550 \mathrm{kWh}$ & $3.59 \mathrm{hr}$ & [26] \\
\hline Cirrus SR22 & IO-550N & $229 \mathrm{~kg}$ & 773 kWh & $3.34 \mathrm{hr}$ & [27] \\
\hline Tecnam P2006T & 2x R912S & $144 \mathrm{~kg}$ & $552 \mathrm{kWh}$ & $4.00 \mathrm{hr}$ & [28] \\
\hline Diamond DA42 & $2 \mathrm{x}$ AE300 & $240 \mathrm{~kg}$ & $1210 \mathrm{kWh}$ & $5.30 \mathrm{hr}$ & [29] \\
\hline NASA X-57 Mod II & 2x JM-X57K & $371 \mathrm{~kg}$ & $43.2 \mathrm{kWh}$ & $0.36 \mathrm{hr}$ & [19] \\
\hline Pipistrel Alpha Electo $\$$ & Dynaden & $120 \mathrm{~kg}$ & $15.6 \mathrm{kWh}$ & $0.12 \mathrm{hr}$ & {$[24]$} \\
\hline
\end{tabular}

The information in Table 3 is deliberately simplified - aircraft can be flown in any number of ways to ensure greater efficiency, depending on the mission and integration strategy. That said, this information does attempt to showcase how heuristics of the aircraft mission performance compares today. This is accomplished through three derived quantities - maximum stored energy mass, maximum shaft work, and time at maximum continuous power (MCP). For the fuel-burning aircraft (the first four rows), the maximum stored energy mass is found from the mass of the fuel when the fuel tanks are filled to maximum capacity. For the electric aircraft (the last two rows), this quantity is just the reported mass of the battery packs. The maximum shaft work is found by multiplying the maximum stored energy times the efficiency from Table 2 for the associated powertrain. For the fuel-burning aircraft, the maximum energy stored is found by multiplying the fuel mass times the approximate lower heating value of the fuel, whereas for electric aircraft, the stored energy is estimated from the referenced useful energy in the batteries. Finally, the time

it The electric motor efficiencies for the Joby and Siemens motors are estimated from available data; unfortunately, true battery-to-shaft power efficiency numbers are not yet available. Hence, $92 \%$ is presented here as a credible estimate based on test data and similarity to other published efficiency numbers.

$\$$ The most easily accessible references to the SP260D motor indicate a mass of 50kg; however, data obtained by the author from a publicly-available fact sheet at a European trade show in 2015 indicate that the inverter adds an additional $10 \mathrm{~kg}$.

$\S$ The data presented here for the Alpha Electro is based off publicly available reports from the Pipistrel WATTsUP prototype. Publicly available reports indicate that production versions of the Alpha Electro do not use the Siemens Dynaden motor. 
at MCP, perhaps the most contrived metric, is simply the time that the motors could be operated at maximum continuous power from Table 2 before the maximum shaft work available would be exhausted. Though this is a crude metric for endurance or range, this metric shows the challenge with electric aircraft - whereas the mass of the stored energy is comparable to that of the fuel-burning aircraft, the time available for operation is significantly reduced.

\section{B. Analysis}

The data from the previous subsection indicates the well-known trade for aviation power architectures - lighter solutions tend to have reduced efficiency (and therefore higher recurring operating costs due to increased energy consumption), but more efficient architectures are heavier and reduce the mass available for useful operation (e.g. payload). To better illustrate this point, this data is further generalized in Fig. 3. Here, the entire energy + powertrain system mass is amortized into a specific power number based on two durations at maximum continuous power: 0.5 hours and five hours. This assumes that the battery-electric systems are "rubberized;" that is, more batteries could be added at the same specific energy as the installed packs on these aircraft (much like adding fuel).

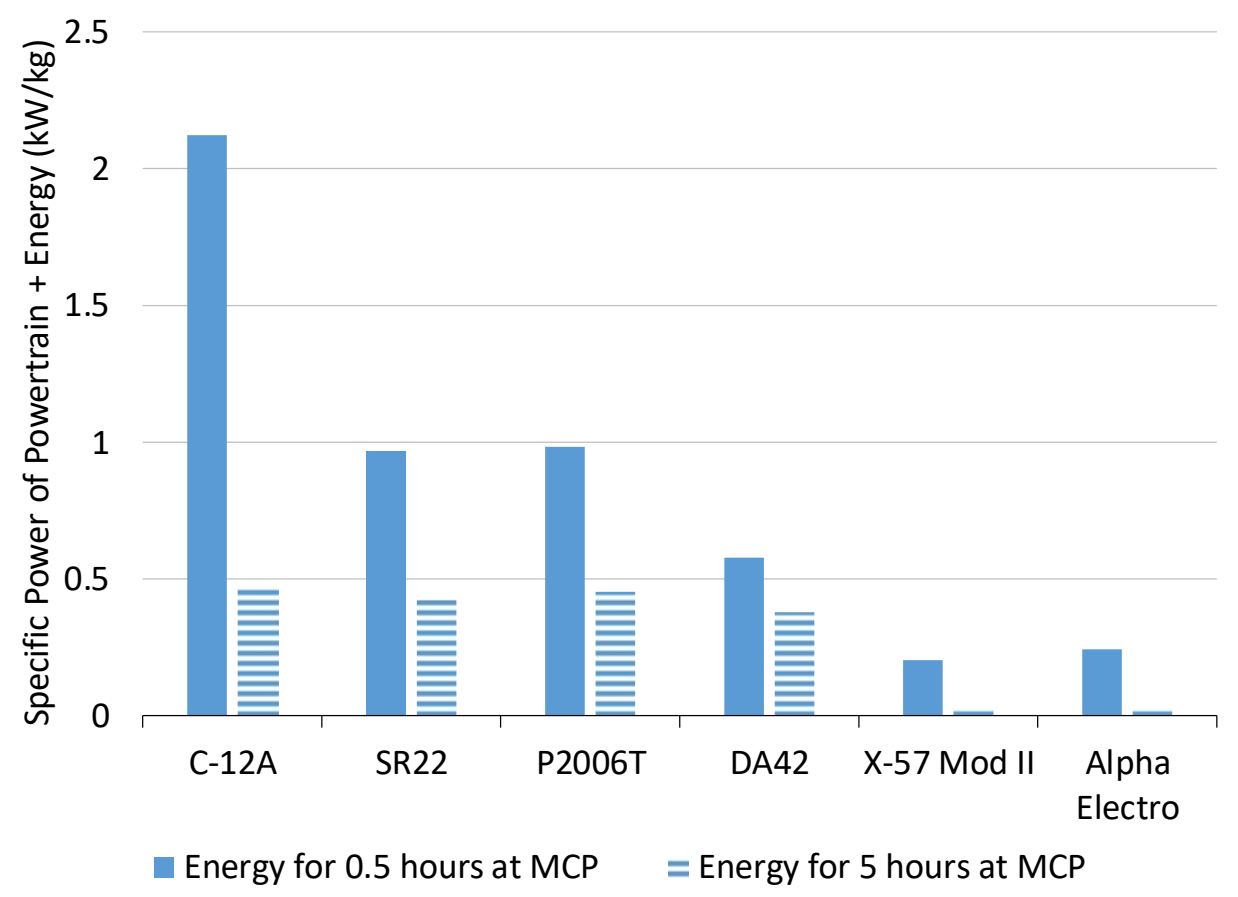

Fig. 3 Specific power of energy + powertrain for $0.5 \mathrm{hr}$ and $5 \mathrm{hr}$ operation at MCP for example aircraft.

To complement this data, the relative energy consumption of each aircraft is shown in Fig. 4. In this case, the relative energy use for the "Aircraft" column is the inverse of the efficiency data in Table 2. The "U.S. Energy Source (2015)" column corrects the "Aircraft" index for the two electric aircraft (X-57 Mod II and Alpha Electro) by dividing by the average efficiency of the U.S. Electrical Grid in 2015, derived from data in Table 1. This represents the total amount of energy used from the sources on the left side of Fig. 2. 


\section{5}

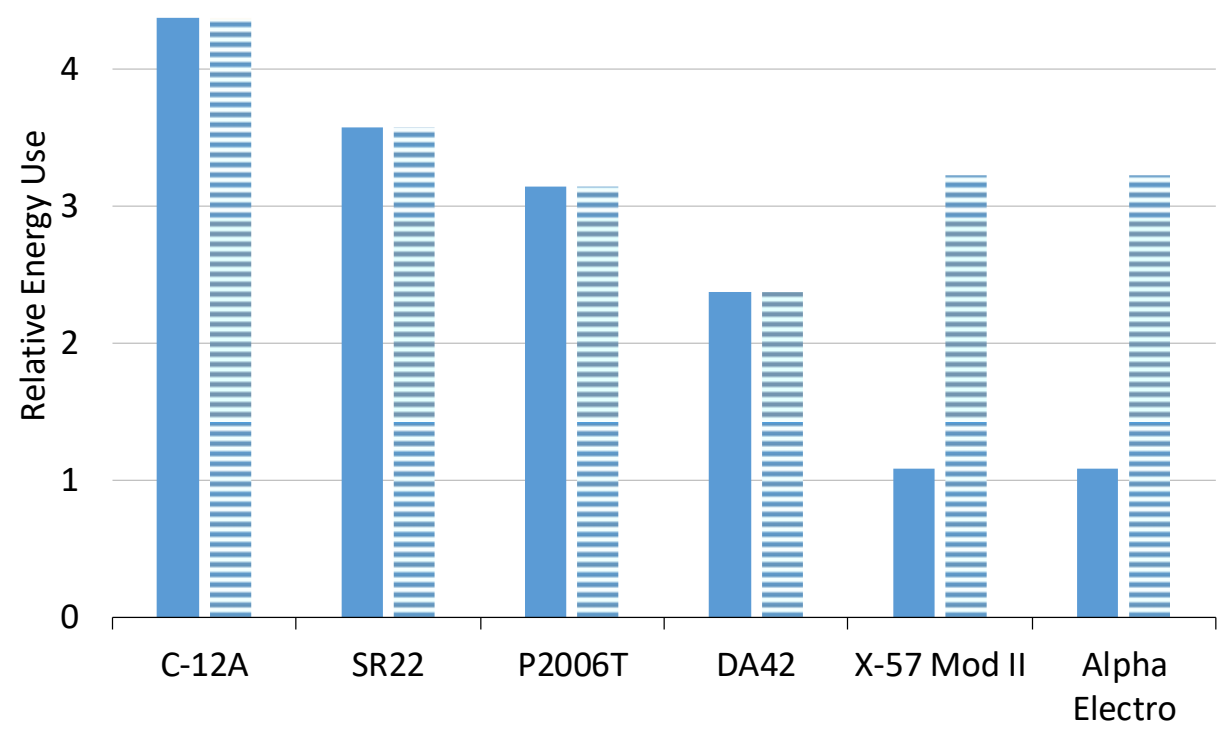

aircraft Only = U.S. Energy Source (2015)

Fig. 4 Relative energy use for example aircraft, considering aircraft-only and U.S. energy system source.

The relative energy use values may speak to system-level efficiency and, at a first-order, emissions, but they do not capture operating costs due to the different energy sources. Retail energy costs are tracked by the U.S. Department of Energy per the Alternative Fuels Data Center (AFDC) [30]. Though the AFDC report does not include jet fuel and aviation gasoline and only considers retail costs, it does help provide data on the types of fuels that these aircraft could use. A sample of the AFDC data collected over nearly two decades is shown in Fig. 5 for retail prices versus a gallon ${ }^{* * *}$ of gasoline equivalent (GGE) energy.

Several noticeable features are apparent from this data. First, electricity and natural gas prices are significantly less volatile than diesel and gasoline prices. Second, when corrected for efficiency (see footnote), retail electricity prices per unit energy are generally the highest and natural gas prices are generally the lowest. The latest data (January 2018) can be used to correct the relative energy use in Fig. 4, as show in Fig. 6. Here, jet fuel and diesel use the AFDC “diesel" price of $\$ 2.63$ per GGE, gasoline is priced at $\$ 2.50$ per GGE, and electricity is priced at $\$ 4.11$ per GGE (approximately $\$ 0.125$ per kWh). The data in Fig. 6 is then the product of these GGE prices with the aircraft-only relative energy use. It shows that, despite changes in the retail price of the stored energy media, the electric concepts still have the potential to have the lowest operating costs. ${ }^{\text {it }}$

\footnotetext{
${ }^{* * *}$ Gallons are used here to maintain easy correlation with AFDC data.

It† This is a knowingly simplified exercise; lower prices for energy are available for large volume operations, and regional variation is high. Aircraft may be designed such that they require far less energy in cruise, as is one of the design goals associated with later "mods" of the X-57 (as compared to "Mod II," shown in the figures in this paper). The energy prices in this exercise exclude jet fuel and aviation gasoline and instead use equivalents (diesel and automotive gasoline). The intent is to be illustrative, not to fully exercise all possibilities.
} 


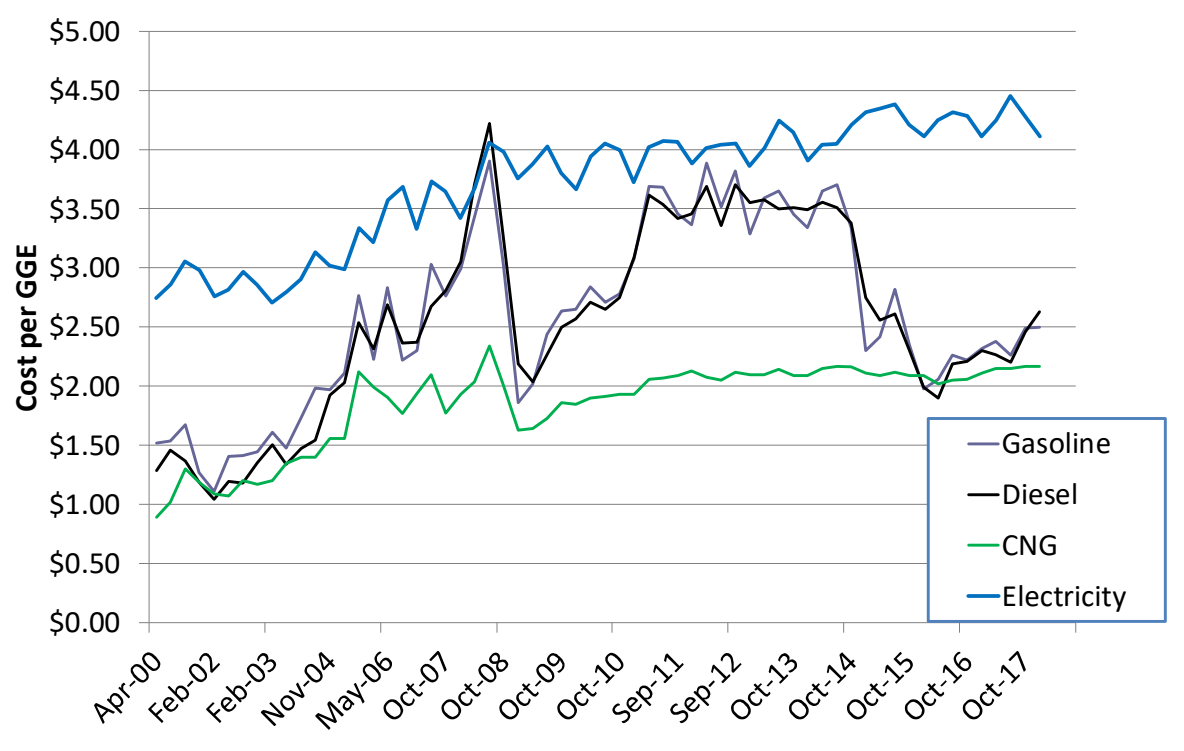

Fig. 5 Historical fuel price data $\$$ (CNG: Compressed Natural Gas).

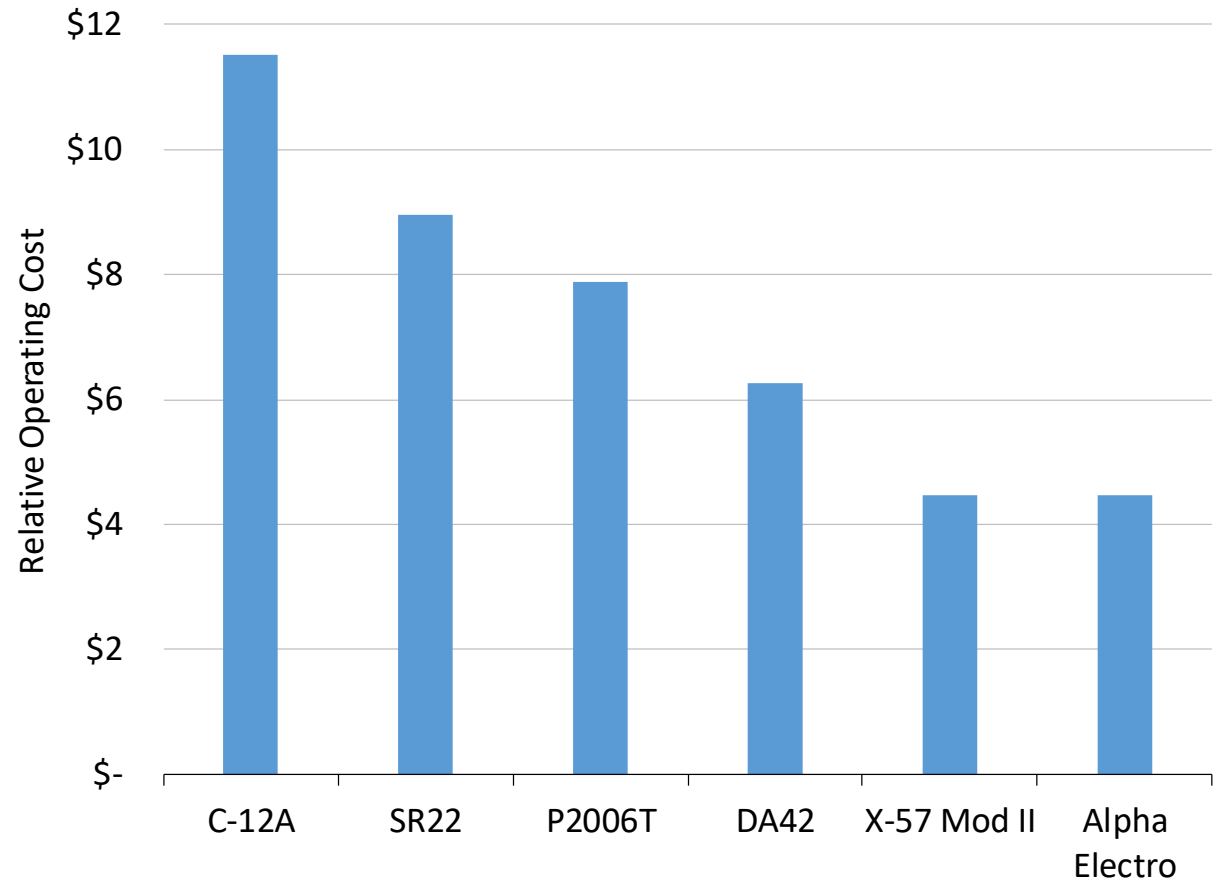

Fig. 6 Relative operating costs for example aircraft.

\$t The "electricity" data in this chart has been multiplied by a factor of 3.4 vs. available AFDC data. This is because the AFDC states "Electricity prices are reduced by a factor of 3.4 because electric motors are approximately 3.4 times as efficient as internal combustion engines." Given that the comparison in this section already accounts for differences in efficiency, electric prices are multiplied by this factor to provide a level comparison. 


\section{Bridging the Gap}

The simple analysis in the previous section is presented to illustrate the challenge with small aircraft. Namely, the efficiency of electric motors has great potential to reduce operating costs related to energy use during the mission but only if the size of the aircraft is appropriately matched to the mission. For traditional aircraft, longer ranges are a necessity for increased utility, and this range comes at higher operational costs (the electric solutions simply cannot yield the range with acceptable vehicle size). For emerging markets, such as UAM and sUAS, the shorter ranges allowable by these missions may not substantially penalize heavier solutions, if they yield reduced operating cost. Although aircraft like the X-57 Mod II and Alpha Electro do not have a combined specific power that is superior to the combustion-based concepts (considering powertrain and energy system), they have enough payload and range capacity to accomplish useful missions. Referring again to Fig. 3, the 0.5 -hr operation at MCP specific power numbers for the purely electric concepts may be seen as a "floor" for any useful alternatives - any aircraft with a specific power level, considering both stored energy and powertrain, of less than about $0.2 \mathrm{~kW} / \mathrm{kg}$ are likely not going to be remotely competitive, or even enable the design solution to close. However, for such heavy designs to be competitive, the overall energy cost must be lower by a substantial-enough margin to offset the additional penalties associated with a heavier propulsion and energy system.

Referring again to the U.S. energy flow chart in Fig. 2, another challenge emerges. In 2015, petroleum accounted for over $36 \%$ of domestic energy and $92 \%$ of energy used for transportation. In total, petroleum and natural gas accounted for over half of input U.S. domestic energy in 2015. Assuming that the net energy required in the United States will not decrease (the 31.0 Quads of "Energy Services" in Fig. 2), it seems effectively impossible to remove all sources of fossil fuels and still satisfy the demand for net energy, for many years to come. As advances are made in transportation technology in the area of electric propulsion, the impact on the total domestic energy flow - especially sources of energy and the efficiency of conversion into useful work - must be addressed.

One oft-touted solution is to leverage hybrid-electric architectures: using petroleum fuels as the primary energy source and electric powertrains for final transmission into useful work, with a battery sized to handle short periods of high power draw. This can help resolve some of the issues associated with purely electric architectures - the existing transportation energy infrastructure, including energy sources, remains, and more efficient electric configurations are available. However, the end-to-end efficiency of power production from traditional hybrid-electric technology, namely, using a combustion engine and converting the combustion engine shaft power into electricity, introduces yet another layer of loss into the system. For example, consider a hybrid-electric version of the P2006T, shown in Table 4. Such a comparison is useful since the X-57 Mod II is a battery-electric version of the same airframe ${ }^{\S \S}$, though the X-57 Mod II will fly at a slightly higher takeoff weight. Some initial educated guesses are made for a hybrid version of the P2006T at stock takeoff weight ("Hybrid A") and X-57 Mod II takeoff weight ("Hybrid B"). Both hybrids assume the X-57 Mod II electric powertrain is used, along with a single Rotax 912S used to generate electrical energy. Battery mass for both hybrids is assumed at $5 \mathrm{kWh}$ and $200 \mathrm{Wh} / \mathrm{kg}$, and electrical conversion equipment is assumed at $4.6 \mathrm{~kW} / \mathrm{kg}$ (equivalent to the Siemens Dynadyn in Table 2).

\section{Table 4 Notional Comparison of Gasoline, Electric, and Hybrid-Electric Aircraft}

\begin{tabular}{|l|l|l|l|l|}
\hline Metric & P2006T & X-57 Mod II & Hybrid A & Hybrid B \\
\hline Powertrain mass & $122 \mathrm{~kg}$ & $74 \mathrm{~kg}$ & $74 \mathrm{~kg}$ & $74 \mathrm{~kg}$ \\
\hline Powertrain efficiency & $32 \%$ & $92 \%$ & $92 \%$ & $92 \%$ \\
\hline Hybrid engine mass & & & $61 \mathrm{~kg}$ & $61 \mathrm{~kg}$ \\
\hline Hybrid engine efficiency & & & $32 \%$ & $32 \%$ \\
\hline Hybrid-electric conversion mass & & & $15 \mathrm{~kg}$ & $15 \mathrm{~kg}$ \\
\hline Hybrid-electric conversion efficiency & & $95 \%$ & $95 \%$ \\
\hline Battery mass & & $371 \mathrm{~kg}$ & $25 \mathrm{~kg}$ & $25 \mathrm{~kg}$ \\
\hline Fuel mass & $144 \mathrm{~kg}$ & & $91 \mathrm{~kg}$ & $270 \mathrm{~kg}$ \\
\hline Energy + powertrain + hybrid mass & $266 \mathrm{~kg}$ & $445 \mathrm{~kg}$ & $266 \mathrm{~kg}$ & $445 \mathrm{~kg}$ \\
\hline Energy + powertrain + hybrid specific power & $0.52 \mathrm{~kW} / \mathrm{kg}$ & $0.27 \mathrm{~kW} / \mathrm{kg}$ & $0.45 \mathrm{~kW} / \mathrm{kg}$ & $0.27 \mathrm{~kW} / \mathrm{kg}$ \\
\hline Energy + powertrain + hybrid efficiency & $32 \%$ & $92 \%$ & $28 \%$ & $28 \%$ \\
\hline Relative energy use & 3.2 & 1.1 & 3.6 & 3.6 \\
\hline Relative operating cost & $\$ 7.88$ & $\$ 4.47$ & $\$ 9.02$ & $\$ 9.02$ \\
\hline
\end{tabular}

$\$ \$ \S$ The X-57 is being developed in multiple design spirals or "Mods" [11]. X-57 "Mod II" uses the same wing as the Tecnam P2006T and is used to test the electrical system, with the JM-X57K motors in place of the Rotax 912S engines. As such, its performance (other than range) is similar to the P2006T. Later "Mods" introduce the DEP wing.

12

American Institute of Aeronautics and Astronautics 
Overall, Table 4 shows the challenge associated with typical, combustion-based hybrid-electric concepts. In this admittedly simplistic example, the system has additional mass associated with the hybrid equipment (combustion engine, electrical conversion equipment, and small traction battery to handle transient loads). However, additional inefficiencies are introduced into the power train: namely, the 32\% efficient combustion process and the $95 \%$ conversion of that shaft power into electrical work - which must then again be converted back into shaft power at $92 \%$ efficiency. What Table 4 does not account for is the potential for additional aerodynamic savings from innovative aero-propulsive approaches, such as seen with X-57 Mod IV's DEP wing. Still, such savings likely account for no more than a 1.7x improvement in efficiency [19]. As compared to the relative operating cost metric, this brings the hybrid approaches to $\$ 5.30$ - better than the pure combustion solution by about $30 \%$. This is not insignificant, but not necessarily game-changing either, particularly since some of those apparent savings may be reduced due the requirement for a heavier vehicle (which requires more power and more energy to fly).

In 2016, the author was Principal Investigator of a project that investigated the potential for a different kind of hybrid-electric power system as a means to accelerate adoption of electric flight [18]. The proposed architecture leveraged a heavy hydrocarbon fuel (diesel) as the energy storage medium, but instead of combusting the fuel outright, the architecture involved reforming it onboard the aircraft into a fuel stream that could be fed into a Solid Oxide Fuel Cell (SOFC). Given that SOFCs may not process all of the fuel, the remaining reformed fuel stream was combusted and expanded through a turbine in a bottoming cycle, providing SOFC pressurization and additional electrical power for traction or other parasitic system losses [31]. The innovation associated with this particular system indicated that efficiency could surpass $60 \%$ of the lower heating value of the fuel - significantly greater than existing small combustion concepts and far more efficient than the average electrical grid. The resulting power system, including traction battery, could exceed a specific power of $300 \mathrm{~W} / \mathrm{kg}$. This was particularly intriguing, given that the 2015 survey by the National Academies expressed that reformation-based SOFC approaches tend to be $30-40 \%$ efficient and yield a system-level specific power of $100 \mathrm{~W} / \mathrm{kg}$ [1].

How would such a system fit in the continuum of small aircraft power system concepts? At the top level, the overall power + energy system specific power is:

$$
(P / m)_{\text {total }}=\left[\frac{1}{(P / m)_{p}}+\frac{1}{(P / m)_{h}}+t \frac{1}{\eta_{p} \eta_{h} L H V}\right]^{-1}
$$

where $(P / m)_{\text {total }}$ is the specific power of the sum of powertrain, hybrid system, and stored energy components, $(P / m)_{p}$ is the specific power of the powertrain, $(P / m)_{h}$ is the specific power of the hybrid SOFC system, $\eta_{p}$ is the efficiency of the electric powertrain, $\eta_{h}$ is the efficiency of the hybrid SOFC system, and $L H V$ is the lower heating value of the fuel. Table 5 shows a first-order tradespace evaluation of a hybrid system, using the simple metrics derived earlier, with a variation of $(P / \mathrm{m})_{p}$ from $0.2-0.4 \mathrm{~kW} / \mathrm{kg}$ and a variation of $\eta_{h}$ from $50 \%$ to $70 \%$. For this evaluation, $(P / m)_{p}$ is fixed at 1.6 (which represents the electric powertrain with the lowest specific power from Table 2 ), $\eta_{p}$ is fixed at $92 \%$, and $L H V$ is assumed to be that of diesel fuel (about $12.0 \mathrm{kWh} / \mathrm{kg}$ ).

Table 5 Tradespace for Notional Hybrid-Electric Concepts

\begin{tabular}{|c|c|c|c|c|c|}
\hline$(\boldsymbol{P} / \boldsymbol{m})_{p}$ & $\eta_{h}$ & $(P / m)_{\text {total }, t=0.5 \mathrm{hr}}$ & $(P / m)_{\text {total }, t=5 h r}$ & Rel. Energy Use & Relative Op. Cost \\
\hline 0.2 & $50 \%$ & 0.18 & 0.15 & 2.2 & $\$ 5.72$ \\
\hline 0.3 & $50 \%$ & 0.25 & 0.21 & 2.2 & $\$ 5.72$ \\
\hline 0.4 & $50 \%$ & 0.31 & 0.25 & 2.2 & $\$ 5.72$ \\
\hline 0.2 & $60 \%$ & 0.18 & 0.16 & 1.8 & $\$ 4.76$ \\
\hline 0.3 & $60 \%$ & 0.25 & 0.21 & 1.8 & $\$ 4.76$ \\
\hline 0.4 & $60 \%$ & 0.31 & 0.26 & 1.8 & $\$ 4.76$ \\
\hline 0.2 & $70 \%$ & 0.18 & 0.16 & 1.6 & $\$ 4.08$ \\
\hline 0.3 & $70 \%$ & 0.25 & 0.22 & 1.6 & $\$ 4.08$ \\
\hline 0.4 & $70 \%$ & 0.31 & 0.27 & 1.6 & $\$ 4.08$ \\
\hline
\end{tabular}

At these combinations of specific power and efficiency, a hybrid-electric power system with a specific power of at least $0.3 \mathrm{~kW} / \mathrm{kg}$ is necessary to maintain a total specific power of over $0.2 \mathrm{~kW} / \mathrm{kg}$ for the 0.5 and 5 -hour durations. Additionally, at $60 \%$ efficiency, the relative operating cost index (as defined earlier) is nearly that of the purely batteryelectric concepts in Fig. 6 and Table 4. Finally, at 60\% efficiency, the relative energy use index is lower than all but the battery-electric concepts at the aircraft level (Fig. 4) and is lower than all of the concepts when considering the total energy used across the 2015 U.S. energy sources. This indicates that such a hybrid-electric system, if possible, 
could bridge the gap between combustion and battery-electric concepts and nearly dominate battery-electric systems entirely - in total specific power, relative energy use, and relative operating cost.

It is worth noting that although the hybrid-electric SOFC architecture described by Stoia et al. [31] (along with the tradespace listed in Table 5) assumes diesel fuel (from petroleum feedstocks), SOFC technology is tolerant of operating on reformed fuel from a number of hydrocarbon streams. The molecules found in natural gas can be largely auto-reformed in the hot SOFC, eliminating the mass and efficiency loss associated with the large steam reformer in the reference system. Furthermore, natural gas has a higher LHV, and therefore lower mass requirement, than that of petroleum fuels. Per Fig. 5, it is also generally the cheapest fuel, and per the data in Table 1 and Fig. 2, it is the secondlargest source of energy in the United States, behind only petroleum. Hence, such a power architecture could help facilitate adoption of airborne electric propulsion, while enjoying the flexibility to use over half of the energy input into the U.S. with little additional investment in infrastructure.

\section{Conclusion}

Airborne electric propulsion technology is one of the cornerstone technologies for enabling new, transformational aviation transportation markets to emerge. These new markets, notably sUAS, UAM, and short/thin-haul, have the potential to affect global energy use and fundamentally alter how energy is supplied and consumed. This is largely because these new markets do not look to displace today's traditional aviation markets, but rather, displace markets currently dominated by ground vehicles, as well as unlocking latent demand. Though there is surging interest in these sectors, some of the more power-hungry applications represent unique challenges to the entire energy delivery ecosystem. Challenges include: a battery-electric UAM will require as much energy as a U.S. home consumes in a day for a typical, 10-minute trip; power demands to charge these UAM vehicles during high-volume "surge" operations will exceed the electrical load of a typical U.S. grocery store for every vehicle being recharged; and the batteries used to store the energy require a rapid recharge at every short stop, simply since these batteries cannot hold enough energy as compared to traditional fuels. Furthermore, whereas the perception is that purely electric concepts have lower emissions, analysis of the electrical grid as it exists today shows that, at best, pure battery-electric concepts will use approximately the same input energy into the U.S. energy infrastructure as the current petroleum-fueled solutions. Though the U.S. electrical grid is getting more efficient, the addition of carbon-based fuels (namely natural gas) has surpassed the addition of all renewable sources in the United States in the past five years. A wholesale change in energy use will be required in the United States for electric transportation to take off - in $2015,92 \%$ of all transportation sector work and over 36\% of the total energy consumed by the United States was based on petroleum. An additional $29 \%$ of fuel was in the form of natural gas, which has been shown to help generate electricity in the most efficient fashion from non-renewable sources.

Given that these transformational aviation markets target smaller power architectures, a representative set of stateof-the-art aviation power architectures was scrutinized, including several combustion engines (turbine and reciprocating) as well as some recent examples of electric motors for aviation use. These aviation power architectures were viewed in the context of the energy systems used onboard the aircraft to illustrate the vexing challenge associated with electric flight: although electric powertrains have excellent specific power ratings as compared to combustion (particularly reciprocating) solutions and have excellent efficiency, the specific energy of the battery systems are over an order a magnitude lower. This is partially blunted by the short range requirements of the emerging UAM market, though it is seen as a major factor towards limiting growth. In addition, analysis considered the differences in operating costs, finding that although the operating cost of comparable electric aircraft on shorter missions has the potential to be lower, retail price history for electricity typically exceeds that of petroleum fuels and natural gas. This further blunts any operating cost advantage enjoyed by electric aircraft.

This study established the specific power and efficiency that could "bridge the gap" between combustion-based powertrains and battery-electric systems. A tantalizing benefit of hybrid-electric technology is the ability to use the petroleum (and potentially natural gas) energy sources, opening up over half of the input energy supply for the United States. This also allows for the use of the potentially more efficient aerodynamic-propulsion integration strategies enabled by electric powertrains, such as DEP, resulting in less net power/energy required for flight. Unfortunately, hybrid systems based on traditional combustion engines add additional layers of mass and inefficiency that do not necessarily provide "game-changing" performance benefits. A parametric analysis of a theoretical hybrid power architecture, based on a recent study of a heavy-fuel, hybrid-electric SOFC concept, shows that a hybrid architecture that can use petroleum or natural gas fuels at $60 \%$ efficiency or more packaged in a power architecture at greater than $0.3 \mathrm{~kW} / \mathrm{kg}$ specific power has the potential to effectively bridge the gap between combustion and battery-electric systems. The development of this new hybrid-electric aviation power architecture is not necessarily the only solution, but rather it should exist with a portfolio of evolving battery-electric and combustion-based systems. 


\section{Acknowledgments}

This work was funded by NASA's Aeronautics Research Mission Directorate (ARMD) under the Transformational Aeronautics Concepts Program. In particular, this research was part of the Fostering Ultra-Efficient, Low-Emitting Aviation Power (FUELEAP) subproject of the Convergent Aeronautics Concepts Project. Though this particular research paper was not directly supported by X-57, much data from the X-57 effort, funded under the NASA ARMD Integrated Systems Research Program, Flight Demonstrations and Capabilities Project, is used to support FUELEAP. The author thanks NASA for their continued support of FUELEAP and X-57. The author also wishes to thank the Aeronautics Systems Analysis Branch, part of the Systems Analysis and Concepts Directorate of NASA's Langley Research Center, for their support of this effort. The generalities and trends expressed in this document are extrapolated from references as cited, where available, or are otherwise the opinion of the author and not necessarily those of NASA.

\section{References}

[1] National Academies of Sciences, Engineering, and Medicine, Commercial Aircraft Propulsion and Energy Systems Research: Reducing Global Carbon Emissions," That National Academies Press, Washington, D.C., 2016. doi: 10.17226/23490

[2] Bloomberg New Energy Finance, "Electric Vehicle Outlook 2017," https://about.bnef.com/electric-vehicle-outlook/, accessed 10 Mary 2018.

[3] International Energy Agency, "Global EV Outlook 2017,” Paris, France, $2017 . \quad$ Available at: https://www.iea.org/publications/freepublications/publication/GlobalEVOutlook2017.pdf, accessed 10 May 2018.

[4] "Amazon Prime Air," https://www.amazon.com/Amazon-Prime-Air/b?node=8037720011, accessed 16 November 2017.

[5] Moore, M. D., Goodrich, K., Viken, J., Smith, J., Fredericks, B., Trani, T., Barraclough, J., German, B., Patterson, M., "HighSpeed Mobility through On-Demand Aviation," AIAA 2013-4373, $13^{\text {th }}$ Aviation Technology, Integration, and Operations Conference, AIAA AVIATION Forum, Los Angeles, CA, August 2013. doi: 10.2514/6.2013-4373

[6] "Pipistrel: the freedom of flight," http://www.pipistrel.si/, accessed 16 November 2017.

[7] Uber Technologies, "Fast-Forwarding to a Future of On-Demand Urban Air Transportation," San Francisco, CA, 27 October 2016. Available at https://www.uber.com/elevate.pdf, accessed 16 November 2017.

[8] Stoll, A. M. and Veble Mikic, G., "Design Studies of Thin-Haul Commuter Aircraft with Distributed Electric Propulsion," AIAA 2016-3765, $16^{\text {th }}$ AIAA Aviation Technology, Integration, and Operations Conference, AIAA AVIATION Forum, Washington, D.C., June 2016. doi: 10.2514/6.2016-3765

[9] Terdiman, D., "Zunum, Back by JetBlue and Boeing, Plans to Deliver Hybrid-Electric Planes in 2022," Fast Company Magazine, 5 October 2017. Available at https://www.fastcompany.com/40474228/zunum-backed-by-jetblue-and-boeingplans-to-deliver-hybrid-electric-planes-in-2022, accessed 16 November 2017.

[10] United States Environmental Protection Agency, "Fast Facts: U.S. Transportation Sector Greenhouse Gas Emissions, 19902015," Office of Transportation and Air Quality, EPA-420-F-17-013, July 2017. Available at https://nepis.epa.gov/Exe/ZyPDF.cgi?Dockey=P100S7NK.pdf, accessed 16 November 2017.

[11] Borer, N. K., Patterson, M. D., Viken, J. K., Moore, M. D., Clarke, S., Redifer, M., Christie, R., Stoll, A., Dubois, A., Bevirt, J., Gibson, A., Foster, T., Osterkamp, P., "Design and Performance of the NASA SCEPTOR Distributed Electric Propulsion Flight Demonstrator," AIAA-2016-3920, $16^{\text {th }}$ AIAA Aviation Technology, Integration, and Operations Conference, AIAA AVIATION Forum, Washington, D.C., June 2016. doi: 10.2514/6.2016-3920

[12] Lawrence Livermore National Laboratory, "Energy Flow Charts: Charting the Complex Relationships among Energy, Water, and Carbon," https://flowcharts.llnl.gov, accessed 16 November 2017.

[13] U.S. Energy Information Administration, "Monthly Energy Review," https://www.eia.gov/totalenergy/data/monthly/, accessed 17 November 2017.

[14] "Breaking New Ground in Energy Efficiency," Power Engineering, 20 June 2016, http://www.powereng.com/articles/print/volume-120/issue-6/features/breaking-new-ground-in-energy-efficiency.html, accessed 17 November 2017.

[15] McDonald, R., and German, B., “eVTOL Stored Energy Overview,” presented at Uber Elevate Summit 2017, Dallas, TX, April 2017. Available at: https://www.uber.com/info/elevate/summit2017, accessed 8 May 2018.

[16] U.S. Energy Information Administration, "How much electricity does an American home use?" https://www.eia.gov/tools/faqs/faq.php?id=97\&t=3, accessed 8 May 2018.

[17] Energy Star, "Supermarkets: An Overview of Energy Use and Energy Efficiency Opportunities," https://www.energystar.gov/sites/default/files/buildings/tools/SPP $\% 20$ Sales $\% 20$ Flyer $\% 20$ for $\% 20$ Supermarkets $\% 20$ and $\% 20$ Grocery\%20Stores.pdf, accessed 8 May 2018.

[18] Borer, N. K., Nickol, C. L., Jones, F. P., Yasky, R. J., Woodham, K., Cagle, C. M., Fell, J. S., Litherland, B L., Loyselle, P. L., Provenza, A. J., Kohlman, L. W., Samuel, A. G., "Overcoming the Adoption Barrier to Electric Flight," AIAA-2016-1022, AIAA SciTech 2016, San Diego, CA, January 2016.

[19] National Aeronautics and Space Administration, "X-57 Critical Design Review," Edwards, CA, November 2016. Available at: https://www.nasa.gov/X-57/technical/index.html, accessed 8 May 2018.

[20] Meier, N., “Civil Turboshaft/Turboprop Specifications,” http://www.jet-engine.net/civtsspec.html, accessed 7 May 2018. 
[21] Continental Motors, "Continental Aircraft Engine: Permold Series Engine Installation and Operation Manual, IO-550-A, -B, -C, -G, -N, -P-, -R,” Publication OI-16, Mobile, AL, August 2011.

[22] BRP-Powertrain GmbH\&Co, “Operators Manual for ROTAX® Engine Type 912 Series,” ref. no. OM-912, Austria, 2015.

[23] Austro Engines, "AE300 Key Benefits," http://austroengine.at/uploads/pdf/mod products1/AE300 Technical Data Sheet.pdf, accessed 7 May 2018.

[24] Urlacher, J.-M., "Electric circuites: Slovenian company Pipistrel makes the electric aircraft a serious proposition," http://www.pipistrel.si/en/file/download/683 f177bc091f05/2015-0115\%20Article\%20Alpha\%20Trainer\%20in\%20Pilot\%20HQ.pdf, accessed 7 May 2018.

[25] Siemens AG, "Aerobatic Airplane 'Extra 330LE' with world-record electric motor from Siemens," https://www.siemens.com/press/pool/de/events/2016/corporate/2016-12-innovation/inno2016-aerobatic-airplane-e.pdf, accessed 7 May 2018.

[26] National Aeronautics and Space Administration, "NASA Armstrong Fact Sheet: B200 King Air Mission Support/Research Aircraft," https://www.nasa.gov/centers/armstrong/news/FactSheets/FS-099-DFRC.html, accessed 7 May 2018.

[27] Cirrus Design Corporation, "Pilot's Operating Handbook and FAA Approved Airplane Flight Manual for the Cirrus Design SR22," P/N 13772-001, Duluth, MN, October 2003.

[28] Costruzioni Aeronautiche Tecnam S.r.1, "P2006T - Aircraft Flight Manual," Doc. No. 2006/044, 4 $4^{\text {th }}$ Ed - Rev. 0, Italy, 2015.

[29] Diamond Aircraft, "DA42-VI," https://www.diamondaircraft.com/aircraft/da42/, accessed 7 May 2018.

[30] U.S. Department of Energy, Alternative Fuels Data Center, "Fuel Prices," U.S. Department of Energy, Alternative Fuels Data Center, "Fuel Prices," U.S. Department of Energy, Alternative Fuels Data Center, "Fuel Prices," https://www.afdc.energy.gov/fuels/prices.html, accessed 8 May 2018.

[31] Stoia, T. R., Atreya, S., O’Neil, P., Balan, C., "A Highly Efficient Solid Oxide Fuel Cell Power System for an All-Electric Commuter Airplane Flight Demonstrator,” AIAA-2016-1024, AIAA SciTech 2016, San Diego, CA, January 2016. 